\title{
The role of Chinese National Steering Committee of Optics and Photonics (CNSCOP)
}

Xu Liu, Baozhen Ge, Shiqiao Qin, Xiangdong Liu, Xiaojie Zhang, et al.

Xu Liu, Baozhen Ge, Shiqiao Qin, Xiangdong Liu, Xiaojie Zhang, Yaocheng Shi, "The role of Chinese National Steering Committee of Optics and Photonics (CNSCOP)," Proc. SPIE 10452, 14th Conference on Education and Training in Optics and Photonics: ETOP 2017, 1045229 (16 August 2017); doi: $10.1117 / 12.2269409$

SPIE Event: 14th Conference on Education and Training in Optics and Photonics, ETOP 2017, 2017, Hangzhou, China 


\title{
The role of Chinese National Steering Committee of Optics and Photonics (CNSCOP)
}

\author{
Xu Liu ${ }^{1}$, Baozhen $\mathrm{Ge}^{2}$, Shiqiao Qin ${ }^{3}$, Xiangdong Liu ${ }^{1}$, Xiaojie Zhang ${ }^{1}$, Yaocheng $\mathrm{Shi}^{1}$ \\ 1 College of Optical Science and Engineering, Zhejiang University, China \\ 2 School of Presision Instrument\& Opto-Electronics Engineering, Tianjin University, China \\ 3 College of Optical Science and Engineering, National University of Defense Technology, China
}

\begin{abstract}
The Chinese National Steering Committee of Optics \& Photonics (CNSCOP) is appointed by the ministry of education of China. The members of the committee are selected from 18 representative domestic Universities, 4 Chinese Academic Institutes and major enterprises. Through designing National high education standards for optic and Photonics; establishing Teacher's training Center; Organizing National annual conference on Optics and Photonics education; setting up the Optics\&Photonics Teaching Resource Sharing Platform etc., the CNSCOP has developed many process in order to improve the Chinese optical education quality and to promote the high achievements of students for whole country. In this paper, we will give brief introduction of all these activities.
\end{abstract}

Keywords: National Steering Committee of Optics \& Photonics of China, Optics and Photonics education, Platform, Activities

\section{BACKGROUND OF CNSCOP}

The high education in China has been developed so rapidly in the last 20 years. Currently, there are more than two thousand universities and colleges in China, among them, more than 220 universities and colleges have programs or even disciplines in the optics and photonics or optical engineering for undergraduate education, and more than 80 universities provide mater degree program for optical engineering. The programs for the undergraduate of different universities have similar but some different title, for example: optical engineering, optics and photonics or optoelectronics and Optical Information techniques etc.. These universities and colleges have different student's qualities levels and different education training objectives, and in current state some universities or college even in poor education conditions, not only teachers quality, but also engineering education facility, and the experimental condition. The high quality teaching resources (including teachers resource, social resource and textbook, and program and experiment etc. are concentrated greatly in the $15 \%$ top university, and $90 \%$ students are distribute in the other $85 \%$ universities). Face to this situation, in order enhance the high education quality, the Ministry of Education of China has organized "The Ministry of Education Teaching Steering Committee" (NTSC) to coordinating the high education of the different universities all over the country in major disciplines or programs. NTSC is composed by the famous experts of the best universities, academic institutions and famous industries in the corresponding field China, The NTSC also contains some members as the representative form different level university so that to get different opinion form different university. The NTSC are asked to investigate the situation of university education of the corresponding discipline in China, and give suggestion to the Ministry of Education, about the evaluation of research, advice, guidance, assessment, services on undergraduate teaching and so on. The main tasks of the committee are:

- To organize and conduct theory and practice of undergraduate teaching.

- To provide advice and recommendations to the Ministry of Education on the work of professional disciplines colleges and universities, teaching materials, teaching laboratory construction and teaching reform.

- To develop the professional standards of education or the quality of teaching standards.

- To evaluate the undergraduate teaching program and consulting Undergraduate education.

14th Conference on Education and Training in Optics and Photonics: ETOP 2017, edited by Xu Liu,

Xi-Cheng Zhang, Proc. of SPIE Vol. 10452, 1045229 • ( 2017 ICO, IEEE, OSA, SPIE

CCC code: $0277-786 X / 17 / \$ 18 \cdot$ doi: $10.1117 / 12.2269409$ 
- To organize teacher training, academic discussions and exchange of information and so on.

- $\quad$ To undertake other tasks commissioned by the Ministry of Education.

The Chinese Steering committee of optics and photonics (CNSCOP) discipline was set up in 2013. The members of the committee are selected from 18 representative domestic Universities, 4 Chinese Academic Institutes and major enterprises, and is changed every 4 years. The task of CNSCOP in the period of 2013-2017 is to organize all the universities and colleges who has the discipline or program in optics and photonics together, to found a big optics and photonics undergraduate education and teaching community, exchange the teaching experience, design the national teaching program standard in the discipline, evaluate the teaching program and curricular, present the advice or policy to the Ministry, and speed up the undergraduate education quality in the field of optics and photonics in China. In the paper, we are going to present the last four years activities of CNSCOP, and the role of in the quality control in optics and photonics.

\section{NATIONAL OPTICS AND PHOTONICS HIGH EDUCATION STANDARDS}

Just as mention above, the university and the students are with different levels, it is important to set up the lowest requirement for the program. Thus, we have to design the National program standards for Optics and Photonics. The standard proposed the minimum education resource, and fundamental curriculum should be satisfied and the minimum academic process. All the university who want to provide Optics and Photonics program must satisfy this standard.

The standard includes the following five parts:

1) Education target

2) Education program

3) The requirement of the teachers

4) Education facility

5) Quality control

It is first time the CNSCOP to design the national standard, so that we first investigate all the universities who provide optics and photonics program, and then analysis these universities, and regroup them into different characteristics:

a. Undergraduate Education for Research-oriented universities

b. Undergraduate Education for Teaching-oriented universities

c. Undergraduate Education for Technology-oriented universities

For each kind of universities, some typical universities are selected as the representative to design and propose the national optics and photonics education standards. This standard is then adapted to all the Chinese universities who has the undergraduate program of optics and Photonics. The main parts of the standard include:

1) Course Program. The standard provides a list of major courses which must be coved by the optics and photonics program. The coursed can be divided into three kinds: general studies, disciplinary basics, and electives for majors. The general studies include advanced mathematics, engineering mathematics, physics and other basic content. The colleges and universities can be based on their own personnel training to improve the positioning of mathematics, physics (including experimental) teaching requirements to strengthen the students' mathematical and physical basis. The disciplinary basics should cover engineering graphics, electronic circuits / electronic technology, computer technology, signal and systems, electromagnetic fields / electromagnetic fields and waves and other core areas of knowledge. The electives for majors should include physical optics, applied optics, optoelectronics, photoelectric detection, laser principle, information optics. Different professional courses should cover the corresponding knowledge areas, the professional courses can be selected according to the college/university situation and appropriate supplement.

2) Teachers. Teachers who work in the professional teaching work should have one of the following conditions: (1) Bachelor degree in electronic information or $\mathrm{PhD}$ degree is optical engineering; (2) has been engaged in the professional teaching, research work in related subjects for more than 5 years; (3) has access to optical and 
photonic related industries national or international qualification or certification. Teachers should have sufficient teaching ability to carry out scientific research, technology development, engineering practice, participate in academic exchanges, to meet the needs of professional teaching. All full-time teachers are required to obtain a teacher's certificate. Teachers should undertake at least one undergraduate course or specialized course, guide graduation design or professional practice, etc., for the development of students to provide the necessary guidance.

3) Quality Control. The universities which are qualified to have an undergraduate program for optics and photonics must have the physical laboratory, electrical and electronic laboratories, electronic information professional basic laboratory, and professional laboratory. The value for the experimental teaching equipment should be more than 5000 yuan/each student. The universities should have a good equipment management, maintenance and update mechanism. The average annual update equipment value should be higher than $10 \%$, the existing equipment integrity rate should be $95 \%$, to meet the experimental teaching needs. Basic and professional basic course experiments to promote a group of people, special circumstances, each group does not exceed 2; comprehensive experiment, large-scale instrument experiment each group no more than 4 people, in order to improve students' independent thinking and independent operation ability.

\section{NATIONAL TEACHERS' TRAINING CENTER}

There are more than 200 universities have the undergraduate program for optics and photonics. There are also universities starting to have optics and photonics program each year. The quality of the teachers is very important for the undergraduate programs. The teaching of optics and photonics, critical fields at the core of today's world-wide technological infrastructure, must continually be upgraded and renewed in order to meet the growing demands of research, science and industry. The real situation in today's optics and photonics education program is something like, $15 \%$ top universities have the $85 \%$ high level teachers. Thus, one major task for CNSCOP is to improve the teaching ability by bring together leading optics and photonics educators from all levels and orientations to discuss, demonstrate and learn about new developments and approaches to teaching in these fields.

CNSCOP has set up a center for teacher training. The teacher training center is organized by Yanshan University, which locates in Qinhuangdao of North China. The training program was scheduled during the summer holiday so that the teachers can have free time to join. Founded in year 2015, the training program has been held successfully twice. Around 100 teachers who are major in optics and photonics joined the program; most of them are young teachers. The teachers from some top universities such as Zhejiang University, Huazhong University of Science and Technology, Tianjian Universities have been invited to give talks to all the participants. During the 1 week training program, the senior teachers introduced their experiences in teaching some major optics and photonics courses such as applied optics, optical communications, and opt-electronic measurements. Most of the invited teachers are the lectures of national-level quality course.

The teachers, especially the young teachers are also given the opportunities to give a lecture during the training program. The senior teachers will give suggestions on the teaching material, teaching methods and also the teaching process. During the evenings, all the participants have discussions to exchange the experiences and also the concerns for the teaching. Such a national teacher's training center is effective to improve the level of first-line teaching teachers to improve the quality of teaching courses; to build peer-to-peer communication platform to promote mutual learning and mutual exchange.

\section{NATIONAL OPTICAL AND PHOTONICS EDUCATION CONFERENCE}

For the CNSCOP, besides the members of the committee are selected from 18 representative domestic Universities, 4 Chinese Academic Institutes and major enterprises, the representatives from the universities, institutes, presses and also the industries who are interested in the education of the optics and photonics are invited to be associated members of CNSCOP. The CNSCOP has 166 associated members from the universities which have the undergraduate program in optics and photonics and also 12associated members from the industry. National optical and photonics education conferences have been held every year and all these members are invited to join the conference.

The general program for the national optical and photonics education conferences include: (1) Delivering the latest news from the ministry of education; (2) Summarize the annual work for the CNSCOP; (3) Inviting leading optics and photonics educators from all levels and orientations to discuss, demonstrate and learn about new developments and 
approaches to teaching in these fields; (4) Helping professors, students, teachers and professional trainers on how to teach and learn optics and photonics for the future through presentations, panel discussions, workshops.

\section{THE RESOURCE SHARING COURSES SYSTEM}

The CNSCOP has proposed to set up a project: the National Optical education Small Private Online Course ( SPOC) system for optics and photonics discipline, to enhance domestic optical education. We call that SPOC system as the "Tele resource sharing courses for the discipline of Optical engineering in China". We think it is a good technique that can profit the top teaching resources in China to the general student all over China. In This paper, we try to present our first period try in the project.

\subsection{The Concept of On-line to Off-line Teaching Resource Sharing System}

We have just mentioned that in China there are about 220 universities and colleges have set up the discipline in Optics or Photonics, they has basic teaching resource for the students, but they are eagerly to profit the high quality teaching resource of hole China.

How to do it? We try to use a special MOOS system to share the best high quality teaching resource of optics and Photonics in China. If MOOCs are used as a supplement to classroom teaching rather than being viewed a replacement for it, they can increase instructor leverage, student throughput, student mastery, and student engagement. This is the model of SPOC: small private online course. Figure 1 show out the difference between MOOCS and SPOC systems.

To design a SPOC system, organize the best teaching resource (the professor and textbook, course ware, excises experiments etc.) together, to found a high education base for optics and photonics.

We use of online courses (similar MOOC) curriculum of minority students enrolled in the school real implementation. And we choose the small number of school registration (s), in addition to online video and exercises, etc., can also be assisted under other online or offline classroom answering." So that we design this our Tele Teaching resource sharing courses by an On line to Off line SPOC system ( or O2O system).

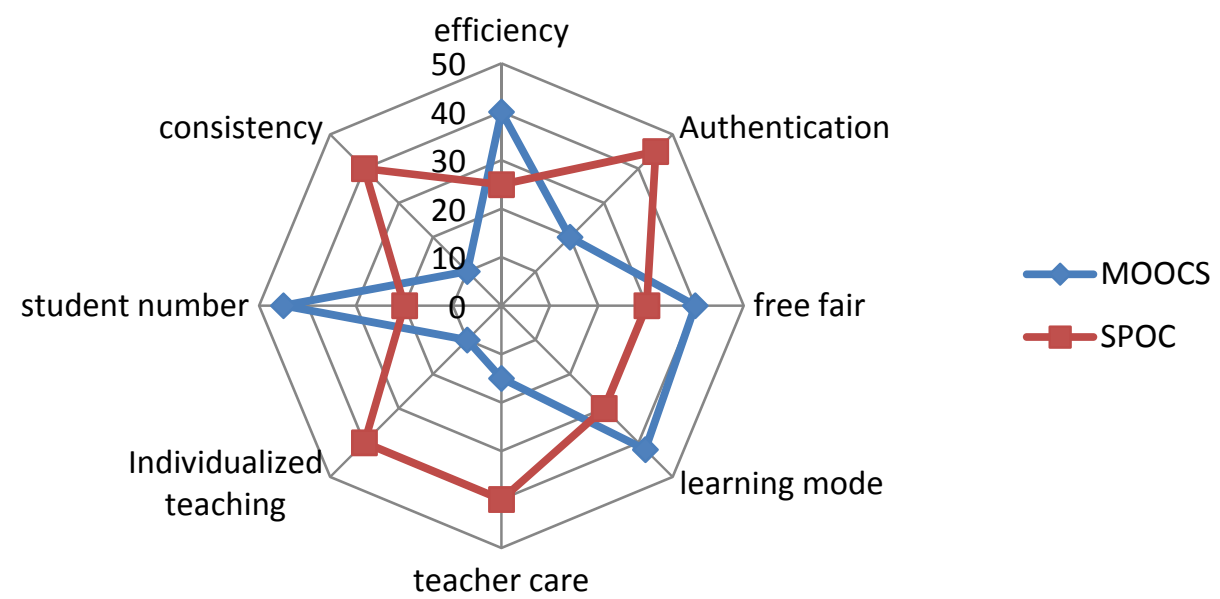

Figure 1 The difference between the SOPC and MOOCs.

\subsection{National Optical Education Small Private Online System}

For setting up the National Optical education SPOC system, we have first choose some common courses which are general courses that will be adapted in the education program of the most universities. So that we choose the most general course: "Applied Optics" (AO) and " Principle of Microprocessor and Interface Technology" (PMIT) two courses for the essay. 
As the pilot courses, we invited the best professors of the two courses, and choose the universities to joint this project. Table 1 show out the current universities joint in the SPOC project. Each university will have same education Syllabus for these two courses, and can acts as the resource offer or resource receiver, sometime both offer and receiver.

We have to design the education process, and the rule for the SPOC education. For resource provider side, the university must open the teacher resource and open the courseware, exercise and homework, experiment etc. to the receiver side, and then send the professor of the course to each receiver side for review the education performance, especially the understanding or mastering result of the receiver side student, and also hold question class in the receiver side. For the receiver, the university has to ask their own teacher to prep learn the course resource form the course's offer, and then guided their own student take the on line course, the student will to do the same home work as the offer' side student, and will take same examination in the off line course.

Some time, the receiver side can just choose individual content use the SPOC system, and the other part is by the conventional education method.

Table 1. The participants of National Optical education SPOC

\begin{tabular}{|c|l|c|}
\hline Courses & \multicolumn{1}{|c|}{ Participants } & Roles \\
\hline AO,PMIT & Zhejiang University & provider/receiver \\
\hline AO & Tianjin University & provider \\
\hline AO & Changchun University of Science and Technology & provider/receiver \\
\hline AO & Beijing Technical college & provider/receiver \\
\hline AO, PMIT & Chongqing University & receiver \\
\hline AO & Wuhan University & receiver \\
\hline AO & Sichuan University & receiver \\
\hline PMIT & Xiamen University of Technology & receiver \\
\hline PMIT & Beijing Information Science \& Technology University & receiver \\
\hline PMIT & Jimei University & receiver \\
\hline AO & Fujian Normal University & receiver \\
\hline AO & Zhejiang Normal University & receiver \\
\hline AO, PMIT & Nanchang Hangkong university & receiver \\
\hline AO,PMIT & Xi an Technological University & provider/receiver \\
\hline AO & Yanshan University & provider/receiver \\
\hline AO,PMIT & Dalian University & receiver \\
\hline AO,PMIT & Huazhong University of Science and Technology & provider/receiver \\
\hline AO & National University of Defense Technology & provider/receiver \\
\hline AO, PMIT & China Jiliang University & receiver \\
\hline PMIT & Zhejiang Sci-Tech University & receiver \\
\hline
\end{tabular}

\subsection{Open Class of Network Video for Optics/Photonics}

Besides the $\mathrm{O} 2 \mathrm{O}$ courses, the CNSCOP also proposes to develop open class of network videos for Optics/Photonics. This series of courses consists of a collection of independent video lectures, including both for the public science courses, including the photoelectric students for the SPOC tutorial version, covering the optical engineering disciplines, applications of optics/photonics and optoelectronic professional education and teaching. The duration of each teaching video is about 25 minutes, including the background description, basic knowledge, application and the latest progress and so on. Video teaching class teachers are domestic and international field of optical engineering has rich teaching and research experience of the top experts and teaching teachers, including the members from the Chinese Academy of Sciences, the Yangtze River scholar, and national boutique class teachers. This series of courses aims to improve the understanding and awareness of optoelectronic disciplines, to help the optical engineering students, researchers or industry practitioners on learning the latest disciplines of technology and knowledge development and interest to help promote the discipline and integration of disciplines. It is an effective supplement and useful extension to the school optoelectronic professional classroom teaching. 

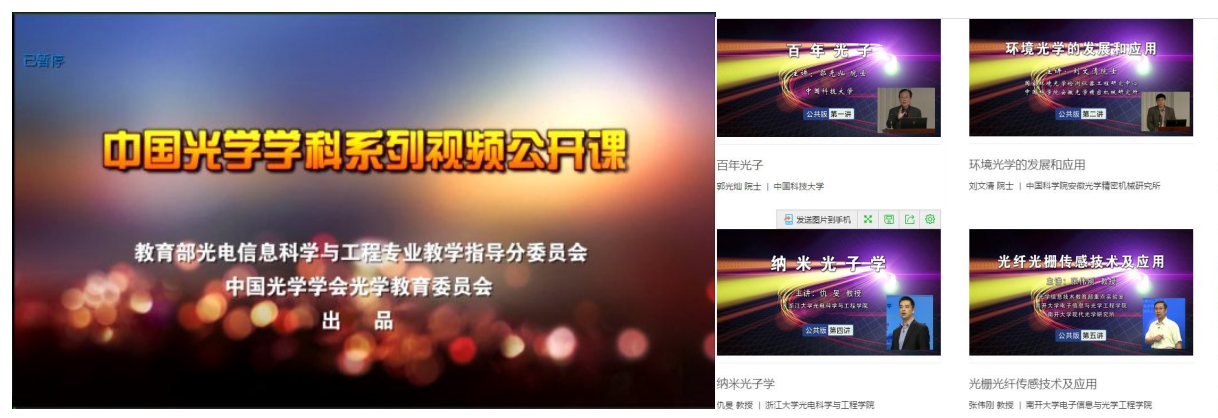

环境光学的发展和应用
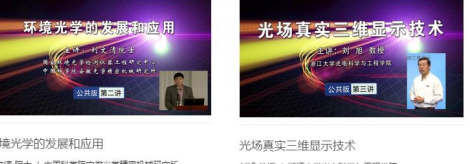

光场真实三维显示技术

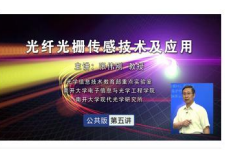

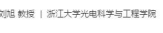

光料光纤传助技术及应用

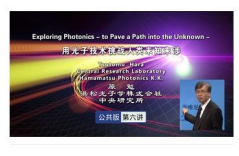

用光子技术挑战人类未知未涉

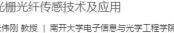

Figure 2 The information for the Open Class of Network Video for Optics/Photonics. http://hep.icourses.cn/zggd.html

\section{CONCLUSION}

In conclusion, the CNSCOP has developed many processes in order to improve the Chinese optical education quality and to promote the high achievements of students major in optics and photonics for whole country. Through various activities such as designing National high education standards for optic and Photonics; establishing Teacher's training Center; Organizing National annual conference on Optics and Photonics education; setting up the Optics\&Photonics Teaching Resource Sharing Platform, the CNSCOP is trying to find effective ways to share the high quality teaching resources to most universities and most students.

\section{ACKNOWLEDGEMENT}

This CNSCOP is under the direct by the ministry of education in China, they have give us so many support and helps in the organization of Committee. All the universities who has program in optics and photonics has actively to joint and contribute in the community. There are so many people works behind to support the committee

\section{REFERENCES}

[1] http://www.icourses.cn/coursestatic/course_6800.html

[2] http://opt.zju.edu.cn/appopt

[3] http://jpkc.zju.edu.cn/k/548

[4] http:// www.cnspoc.com/school/opt

[5] Li Xiaotong, Cen Zhaofeng, Liu Xiangdong, et.al., The resource sharing course applied optics: Flipped class model and MOOC-like construction, Proc. of 2014 national conference in optical and photo-electric professional education and teaching reform[C], The Ministry of Education Teaching Steering Committee of Optics and Photonics 2013-2017. Qinhuangdao, China, 2014: 1-5

[6] Xu Liu, XiangDong Liu, XiaoDong Zheng, XiaoPing Wang and YuanFang Lin, The development of O2O system of resource sharing courses for the discipline of Optical engineering in China. Education and Training in Optics and Photonics: ETOP 2015, Proc. of SPIE Vol. 9793, 97930J - (C) 2015 SPIE, IEEE, OSA, ICO · doi: $10.1117 / 12.2223071$. 